\title{
Next-Generation Covalent Irreversible Kinase Inhibitors in NSCLC: Focus on Afatinib
}

\author{
Vera Hirsh ${ }^{1}$
}

Published online: 30 June 2015

(C) The Author(s) 2015. This article is published with open access at Springerlink.com

\begin{abstract}
First-generation, reversible epidermal growth factor receptor (EGFR) tyrosine kinase inhibitors (TKIs), erlotinib and gefitinib, represented an important addition to the treatment armamentarium for non-small-cell lung cancer (NSCLC) patients with activating EGFR mutations. However, all patients inevitably develop acquired resistance to these agents, primarily due to secondary EGFR mutations, molecular aberrations affecting other signaling pathways, or transformation to small-cell histology. It was hypothesized that development of second-generation TKIs with broader inhibitory profiles could confer longer-lasting clinical activity and overcome acquired resistance to firstgeneration inhibitors. Here, we review the development of afatinib, an irreversible ErbB family blocker that potently inhibits signaling of all homodimers and heterodimers formed by the EGFR, human epidermal growth factor receptor (HER)-2, HER3, and HER4 receptors. In two phase III trials in patients with EGFR mutation-positive NSCLC, first-line afatinib significantly improved progression-free survival (PFS) and health-related quality of life versus standard-of-care chemotherapy. Moreover, in preplanned sub-analyses, afatinib significantly improved overall survival in patients harboring EGFR Del19 mutations. Afatinib has also demonstrated clinical activity in NSCLC patients who had progressed on erlotinib/gefitinib, particularly when combined with cetuximab, and offers 'treatment beyond progression' benefit when combined with paclitaxel versus chemotherapy alone. Furthermore, a
\end{abstract}

Vera Hirsh

vera.hirsh@muhc.mcgill.ca

1 McGill Department of Oncology, Royal Victoria Hospital, 687 Pine Avenue W., Montreal, QC H3A 1A1, Canada recent phase III study demonstrated that PFS was significantly improved with afatinib versus erlotinib for the second-line treatment of patients with squamous cell carcinoma of the lung. The activity of afatinib in both firstline and relapsed/refractory settings may reflect its ability to irreversibly inhibit all ErbB family members. Afatinib has a well-defined safety profile with characteristic gastrointestinal (diarrhea, stomatitis) and cutaneous (rash/ acne) adverse events.

\section{Key Points}

Afatinib is an irreversible ErbB family blocker that potently inhibits signaling from all ErbB family receptor homodimers and heterodimers.

In two large phase III trials, first-line afatinib significantly improved overall survival versus chemotherapy in non-small-cell lung cancer (NSCLC) patients specifically harboring epidermal growth factor receptor (EGFR) Del19 mutations, as well as progression-free survival and patientreported outcomes in patients with EGFR mutationpositive disease regardless of mutation type.

Afatinib has demonstrated improved overall survival and progression-free survival versus erlotinib in patients with squamous cell carcinoma of the lung. It has also demonstrated promising activity in NSCLC patients with brain metastases, in patients who have failed prior chemotherapy and/or first-generation reversible EGFR tyrosine kinase inhibitors, and when continued in combination with paclitaxel beyond disease progression after monotherapy. 


\section{Introduction}

Over the last few decades, many advances have been made in the treatment of non-small-cell lung cancer (NSCLC), including improvements in cytotoxic chemotherapy regimens and the discovery of new targeted therapies [1]. Despite these advances, NSCLC is still difficult to treat. Patients with NSCLC typically present with advanced disease, where localized therapy is not a viable option [2]. Platinum-based chemotherapy, the standard first-line therapy for many patients, can prolong survival by 8-12 months in some cases and improve disease-related symptoms and quality of life (QoL) [3]; however, outcomes are generally poor and tolerability is often a concern [3]. For patients with refractory/relapsed disease, approved second-line treatments include docetaxel, pemetrexed, or erlotinib [3], although survival benefits with these agents are modest [4-6]. The US FDA withdrew approval for gefitinib in this setting following the phase III ISEL (IRESSA ${ }^{\circledR}$ Survival Evaluation in Lung Cancer) study that failed to demonstrate a significant overall survival (OS) benefit over placebo [7]; however, subsequent studies have shown second-line gefitinib to be non-inferior to docetaxel, with improved tolerability [8]. In part, the difficulty of treating NSCLC arises from the strikingly heterogeneous nature of the disease. In recent years, numerous oncogenic driver mutations have been identified in NSCLC, which has led to development of some molecularly targeted anticancer agents [9]. To date, the following have been identified as druggable targets: rearrangements in the anaplastic lymphoma kinase $(A L K)$ gene $(3-5 \%$ of patients) and mutations in the epidermal growth factor receptor $(E G F R)$ [2, 9-11].

EGFR is a member of a family of four structurally related receptor tyrosine kinases, the ErbB family kinases $[12,13]$. In humans, this includes human epidermal growth factor 1 (HER1; EGFR, ErbB1), HER2 (Neu, ErbB2), HER3 (ErbB3), and HER4 (ErbB4). ErbB family proteins form homodimers, heterodimers, and possibly higher-order oligomers $[12,13]$. The normal physiological role of the ErbB family is regulation of cellular proliferation [12]. Dysregulated signaling through ErbB proteins has been associated with the development of a variety of cancers, including NSCLC $[12,13]$. Many patients with NSCLC have somatic mutations of EGFR that lead to aberrant constitutive signaling via EGFR and its downstream networks; these abnormalities have been reported in about $50 \%$ of Asian patients and 10-15\% of Caucasian patients with lung adenocarcinoma [14]. Of the known EGFR mutations, the most common are exon 19 deletions (Del19) and an L858R point mutation (L858R) [15]. Tumors with $E G F R$-activating mutations can become completely dependent on EGFR activity to stimulate downstream cell signaling networks ('oncogene addiction'). In this instance, blockade of EGFR with oral tyrosine kinase inhibitors (TKIs) blocks proliferation and initiates apoptosis [16].

The first-generation reversible EGFR-TKIs, erlotinib and gefitinib, are approved first-line therapies for patients with NSCLC harboring activating EGFR mutations. In randomized phase III trials, both agents demonstrated improved progression-free survival (PFS) and response rates versus standard platinum-based chemotherapy in this setting (Table 1) [17-23]. Unfortunately, however, virtually all patients who respond inevitably develop acquired resistance to these agents, and tumors rapidly regrow [24]. Moreover, neither erlotinib nor gefitinib have demonstrated an OS benefit over chemotherapy [17, 25-30]. Consequently, there has been intensive research into (1) mechanisms of resistance to first-generation inhibitors; (2) development of newer, more potent ErbB receptor family inhibitors that may offer (a) prolonged response in a firstline setting or (b) viable treatment options following the failure of first-generation inhibitors. In this review, we discuss the rationale for, and development of, secondgeneration TKIs with a focus on afatinib an irreversible, ErbB family blocker.

\section{First-Generation Epidermal Growth Factor Receptor (EGFR) Tyrosine Kinase Inhibitors (TKIs) in the Treatment of Non-Small-Cell Lung Cancer (NSCLC)}

First-generation EGFR-TKIs bind reversibly to the kinase domain of the enzyme, inhibiting both mutated and, to a lesser extent, wild-type EGFR [31]. They interrupt EGFR signaling through blockade of autophosphorylation, following competitive binding versus adenosine triphosphate (ATP) at the receptor intracellular catalytic domain [32, 33]. Initial phase III clinical trials of gefitinib versus chemotherapy (IPASS [Iressa Pan-Asia study] and FirstSIGNAL [First-line Single-agent Iressa versus Gemcitabine and cisplatin trial in Never-smokers with Adenocarcinoma of the Lung]; Table 1) [17, 20] were undertaken in patients who were not preselected based on EGFR mutation status; however, subgroup analyses and subsequent independent studies demonstrated that activating EGFR mutations were strongly predictive of improved outcomes with EGFR-TKIs [17, 20, 34, 35]. Consequently, additional phase III studies of gefitinib and erlotinib were conducted in preselected patients with activating EGFR mutations $[18,19,21,23]$, leading to regulatory approval of both agents (Table 1).

In addition to the IPASS and First-SIGNAL trials conducted in Asian patients with advanced NSCLC, significant 


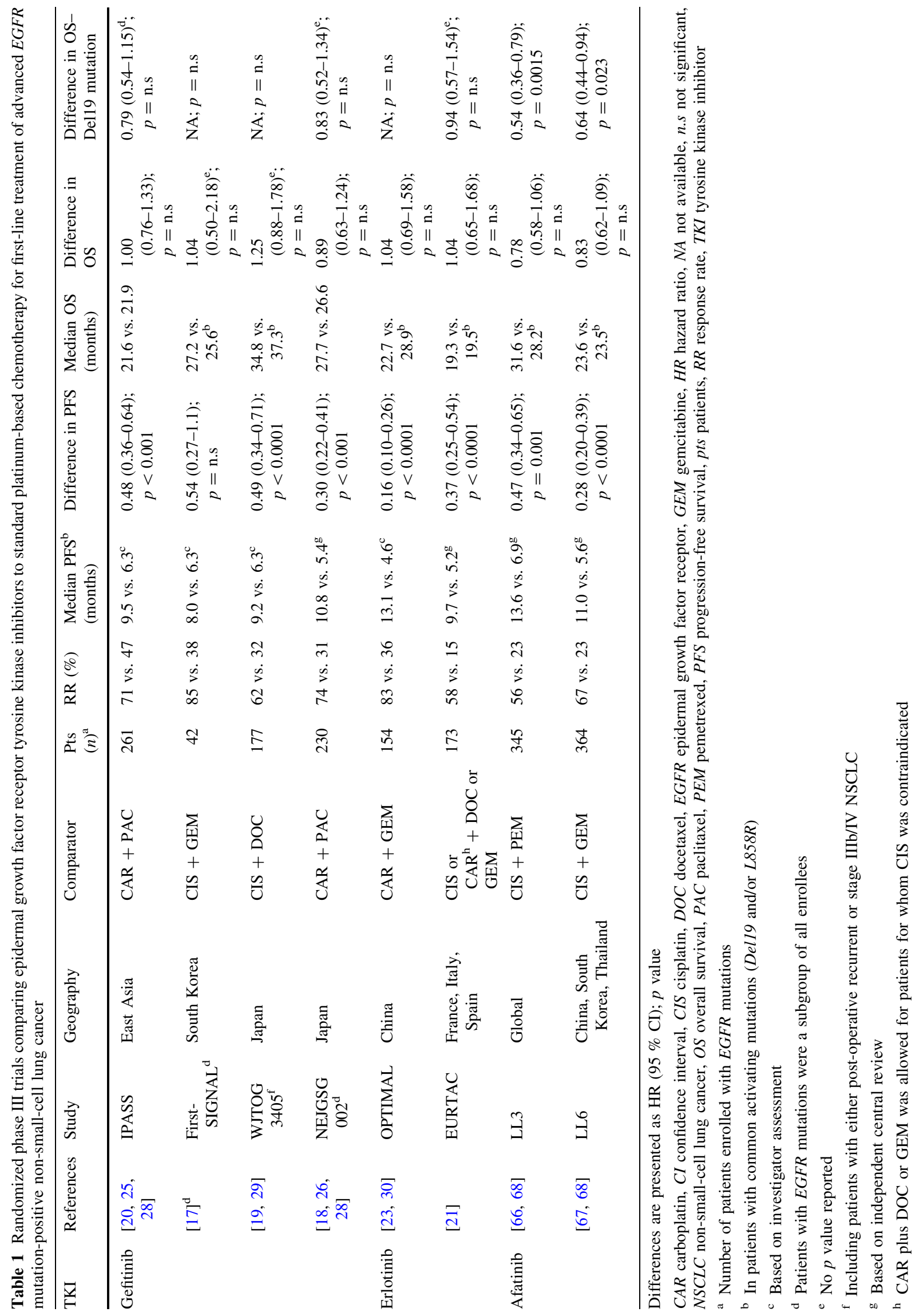


improvements in PFS with first-line gefitinib compared with platinum-doublet chemotherapy were reported in two phase III studies (NEJ002, WJTOG3405) in Japanese patients with EGFR mutation-positive NSCLC (Table 1) $[18,19]$. Currently, gefitinib is approved in Europe for the treatment of locally advanced or metastatic NSCLC with sensitizing EGFR mutations [36]. In the USA, gefitinib is restricted to patients who, in the opinion of the treating physician, are currently benefitting from, or have previously benefitted from, treatment with this agent [37].

In a phase III European trial (EURTAC [European tarceva versus chemotherapy]) comparing erlotinib with platinum-doublet chemotherapy in patients with advanced NSCLC and activating EGFR mutations, a significant improvement in median PFS (Table 1) and better tolerability was observed with erlotinib versus chemotherapy [21]. Similar findings for erlotinib were observed in a clinical trial (OPTIMAL) in Chinese patients [23], and National Comprehensive Cancer Network (NCCN) guidelines were amended in 2011 on the strength of these data. In May 2013, erlotinib was approved by the US FDA for first-line treatment of patients whose tumors have common activating EGFR mutations [38].

Erlotinib and gefitinib are also sometimes recommended as second- or third-line therapy in patients with NSCLC [2]. In the case of erlotinib, this recommendation is independent of mutation status, based on a placebo-controlled, phase III trial in unselected relapsed/refractory NSCLC patients (BR21) [6]. However, subsequent studies have indicated that the activity of erlotinib in second-/third-line settings is largely restricted to patients with activating EGFR mutations. In a phase III trial (TAILOR [Tarceva Italian Lung Optimization tRial]), erlotinib was compared with docetaxel as second-line therapy in patients with NSCLC and wild-type $E G F R$. In this study, PFS was significantly longer with docetaxel than with erlotinib in the overall study population and the subgroup of patients with adenocarcinoma histology; PFS was similar between treatment groups in the subgroup of patients with squamous histology [39]. In another phase III trial (DELTA [Docetaxel and Erlotinib Lung Cancer Trial]), in an EGFR-unselected patient population, erlotinib failed to show an improvement in PFS or OS versus docetaxel in a second-/third-line setting [40]. Taken together, these findings suggest that chemotherapy remains the most effective treatment option (albeit with modest activity) in the majority of EGFR-wild-type patients with relapsed/refractory NSCLC, although further studies with EGFR-TKIs in patients with squamous cell histology independent of EGFR mutation status are ongoing. However, despite the activity observed in the relapsed/refractory setting, chemotherapy, particularly docetaxel, is associated with poor tolerability [39]. Therefore, there remains an unmet medical need for more effective and/or better tolerated second-line treatment options.

\section{Resistance to First-Generation EGFR-TKIs}

Patients with NSCLC tumors harboring EGFR mutations inevitably develop resistance to first-generation EGFRTKIs [24]. The most common resistance mechanism defined to date (50-60\% of patients) is the accrual of a T790M missense mutation in exon 20 (T790M) [41-43]. This abnormality interferes with the binding of inhibitors of EGFR through steric hindrance [44]. Other acquired resistance mechanisms are currently less well understood, although there is evidence that activation of other tyrosine kinase receptors, either due to overexpression or mutations, leads to compensatory signaling via proliferative pathways including the phosphoinositide 3-kinase/protein kinase $\mathrm{B} / \mathrm{mammalian}$ target of rapamycin (PI3K/AKT/mTOR) and Janus kinase 2/signal transducer and activator of transcription 3 (JAK2/STAT3) cascades [45]. Receptors implicated in resistance to EGFR-TKIs include the MET receptor, a trans-membrane tyrosine kinase encoded by the proto-oncogene, MET and the insulin-like growth factor (IGF)-1 receptor [46-48]. Notably, other members of the ErbB family of receptors have also been implicated. Gene amplification or protein overexpression of HER2 can induce resistance to EGFR-TKIs [49]. Furthermore, continuous exposure to first-generation inhibitors can confer overexpression of HER3 as a result of loss of AKT-mediated negative feedback signaling [50]. Efforts to overcome these resistance mechanisms in NSCLC patients have included the development of irreversible ErbB family inhibitors that may provide more durable and prolonged responses in the first-line setting, as well as offering a potential treatment option in patients with acquired resistance to erlotinib/gefitinib. Other proposed, yet poorly understood, mechanisms of resistance include transformation to small-cell histology [43] and epithelial to mesenchymal transition [51].

\section{Second-Generation TKIs: An Overview}

Based on the rationale above, several second-generation TKIs have been assessed in preclinical studies as well as in the clinic in patients with NSCLC. In brief, these include the following.

\subsection{Dacomitinib}

Dacomitinib irreversibly inhibits EGFR, HER2, and HER4 and blocks signaling through all ErbB homodimers and heterodimers [52, 53]. In preclinical studies, dacomitinib was reported to inhibit EGFR signaling in tumors/cells harboring several different EGFR mutations, including $T 790 M$ [52]. Dacomitinib has been assessed in both first- 
line and relapsed/refractory settings in patients with NSCLC. In a recent phase II study, dacomitinib was reported to deliver a median PFS of 18.2 months in patients who had treatment-naïve NSCLC with activating EGFR mutations [54]. A randomized phase III trial comparing dacomitinib and gefitinib in this setting is ongoing (ARCHER [Advanced research for cancer targeted panHER therapy] 1050). However, recent studies with dacomitinib in the relapsed/refractory setting have failed to achieve their primary objectives. In the phase III ARCHER 1009 study, which compared dacomitinib with erlotinib in patients with NSCLC who had previously received up to two chemotherapy regimens, median PFS was 2.6 months in both groups [55]. In the phase III BR.26 trial, which assessed dacomitinib versus placebo in patients who had previously received chemotherapy and a first-generation reversible EGFR-TKI, there was no significant difference in OS between the two treatment arms, albeit PFS was significantly longer in patients who received dacomitinib (median 2.7 vs. 1.4 months; $p<0.0001$ ).

\subsection{Neratinib}

Neratinib is an irreversible inhibitor of EGFR and HER2. In preclinical studies, it was more effective than gefitinib at suppressing cell proliferation in lung cancer cell lines, including cells harboring the $T 790 M$ mutation [56]. Neratinib was assessed in a phase II study of patients with advanced NSCLC who had previously received at least 12 weeks of therapy with gefitinib or erlotinib. Response rates in this trial were very low; $3 \%$ of patients with activating EGFR mutations and no patients with $T 790 M$ achieved an objective response (OR) [57]. A total of $50 \%$ of patients developed grade 3 diarrhea at the previously determined maximum tolerated dose (MTD) of $320 \mathrm{mg} /$ day [58], and the phase II trial dose was subsequently reduced to $240 \mathrm{mg} /$ day.

\subsection{Afatinib}

Afatinib covalently binds to EGFR, HER2, and ErbB4 [59]. Such covalent binding irreversibly inhibits the tyrosine kinase activity of these receptors, resulting in reduced auto- and trans-phosphorylation within the ErbB dimers and inhibition of important steps in the signal transduction of all ErbB receptor family members (Fig. 1). The other ErbB family member, ErbB3, lacks intrinsic kinase activity but forms active heterodimers with other family members, particularly HER2 [60]. Afatinib effectively silences signaling of all ErbB family heterodimers, including HER2/ ErbB3 (Fig. 1) [59]. The irreversible inhibition of multiple ErbB family receptors by afatinib results in more potent and prolonged suppression of receptor kinase activity

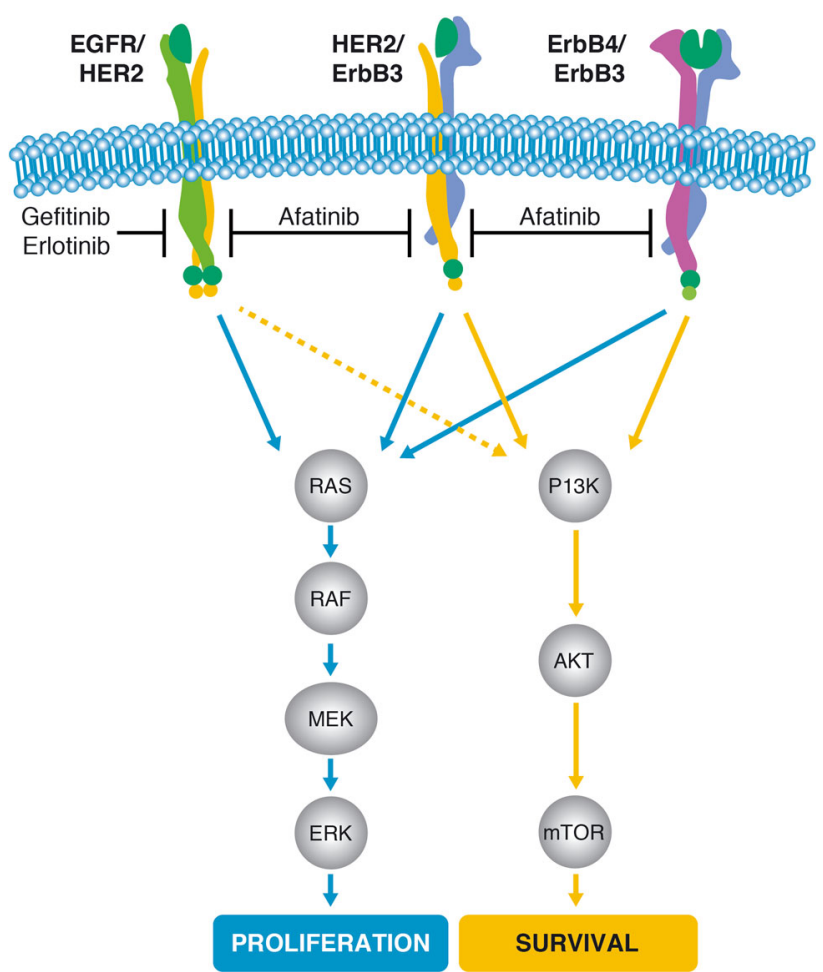

Fig. 1 Irreversible inhibition of ErbB receptor family signaling by afatinib. Covalent binding of afatinib to the ErbB family of receptors inhibits downstream signaling of all homodimers and heterodimers formed by these receptors $[59,61]$. AKT protein kinase B, EGFR epidermal growth factor receptor, $E R K$ extracellular signal-regulated kinase, HER2 human epidermal growth factor receptor 2 (ErbB2), $M E K$ mitogen-activated protein kinase kinase, ITOR mammalian target of rapamycin, $P 13 \mathrm{~K}$ phosphoinositide 3-kinase, $R A F$ rapidly accelerated fibrosarcoma, $R A S$ rat sarcoma

compared with reversible first-generation EGFR-TKIs [31, 59, 61]. Afatinib is currently approved in the USA for the first-line treatment of patients with metastatic NSCLC whose tumors have EGFR exon 19 deletions or exon 21 substitution mutations as detected by an FDA-approved test [62]. Afatinib is also approved for patients with NSCLC in over 40 countries worldwide, including the EU, Japan, Taiwan, and Canada. In the EU, it is indicated for patients with TKI-naïve NSCLC harboring activating EGFR mutations [63]. The remainder of this review focuses on the preclinical and clinical development of afatinib in patients with NSCLC.

\section{Preclinical Development of Afatinib}

In cell-free in vitro kinase assays, afatinib demonstrated potent inhibition of wild-type EGFR, HER2, and ErbB4 at low nanomolar concentrations, whereas reversible TKIs erlotinib and gefitinib only inhibited EGFR (Table 2) [59]. Moreover, both cell-free assays and cell-based proliferation 
assays have shown that afatinib has potent inhibitory activity in the presence of the common EGFR-activating mutations, L858R and Del19 [59, 61]. In contrast with erlotinib and gefitinib, afatinib was also active against NSCLC cells that overexpress HER2 (Table 2).

Afatinib inhibited cellular growth and induced apoptosis in several tumor cell lines, and resulted in tumor shrinkage in xenograft models of various cancer types, including NSCLC, pancreatic cancer, colorectal cancer, and head and neck squamous cell cancer [64]. Afatinib also demonstrated activity in preclinical models of tumor cells resistant to reversible EGFR inhibitors, suggesting that irreversible ErbB family blockade could be effective in patients with reversible EGFR-TKI-resistant disease [64, 65]. Indeed, in cell-free kinase assays, afatinib inhibited EGFR harboring $L 858 R / T 790 M$ at low nanomolar concentrations (half maximal effective concentration $\left[\mathrm{EC}_{50}\right], 9-10 \mathrm{nM}$; Table 2). Furthermore, afatinib inhibited cell growth in cultured lung cancer cells $\left(\mathrm{EC}_{50}, 99 \mathrm{nM}\right)$ and a lung cancer xenograft model harboring L858R/T790M [61, 64]. In comparison, $\mathrm{EC}_{50}$ values for erlotinib and gefitinib against $L 858 R / T 790 M$ were $>500 \mathrm{nM}$ in cell-free kinase assays (Table 2) and $>4000 \mathrm{nM}$ in cultured lung cancer cells [61].

Taken together, the potent irreversible inhibition of signaling from all ErbB family receptor dimers formed by EGFR, HER2, and ErbB4, and preclinical antitumor activity observed in both EGFR-TKI-naïve and resistant cultured cells and xenograft models, provided biological rationale for the evaluation of afatinib in clinical trials.

\section{Clinical Trials of First-Line Afatinib in Patients with NSCLC and Activating EGFR Mutations: LUX-Lung 3 (LL3) and LUX-Lung 6 (LL6)}

\subsection{Trial Design}

The LL3 (LUX-Lung 3; 345 patients recruited globally) and LL6 (364 patients recruited in China, South Korea, and Thailand) trials are the largest randomized, phase III trials ever to be undertaken in treatment-naïve patients with EGFR mutation-positive advanced NSCLC [66-68]. In contrast to the gefitinib and erlotinib registration studies, recruitment was not restricted to patients with tumors harboring Del19 and/or L858R; the trial designs of LL3 and LL6 also incorporated patients with uncommon EGFR mutations (including $T 790 M$, exon 20 insertions, G719X, $S 768 I$, and $L 861 Q$, alone or as complex mutations in two or more exons). Patients were randomized (2:1) to afatinib $(40 \mathrm{mg} /$ day) or up to six cycles of standard-of-care platinum-based chemotherapy (cisplatin + pemetrexed [LL3] or cisplatin + gemcitabine [LL6]; selection based on the regulatory requirements of the different regions). It should be noted that cisplatin + pemetrexed was considered a state-of-the-art chemotherapy regimen when LL3 was designed and represented a more challenging comparator than used in other trials of EGFR-TKIs versus chemotherapy [69].

The primary endpoint of LL3 and LL6 was PFS, by prespecified independent central review; the key secondary endpoint was OS. Both trials fully integrated comprehensive patient-reported outcomes (PROs) related to functional health status/QoL and lung cancer-related symptoms; these were evaluated using the European Organisation for Research and Treatment of Cancer (EORTC) QoL Questionnaire C30 (QLQ-C30) and its lung cancer-specific module (QLQ-LC13) (Table 3) [66, 67, 70].

\subsection{Primary Endpoint: Progression-Free Survival}

First-line afatinib significantly prolonged median PFS versus chemotherapy in both LL3 (11.1 vs. 6.9 months; hazard ratio [HR] 0.58 [95\% confidence interval (CI) $0.43-0.78 ; p=0.001])$ and LL6 (11.0 vs. 5.6 months; HR 0.28 [95 \% CI 0.20-0.39; $\mathrm{p}=0.0001$ ]; Table 1; Fig. 2a/b) $[66,67]$. Furthermore, subgroup analyses showed that the PFS benefit was apparent across most clinically relevant subgroups (age, sex, race, Eastern Cooperative Oncology Group [ECOG] performance status). When the analysis
Table 2 Inhibitory potency of afatinib, erlotinib, and gefitinib against ErbB family members in cell-free kinase assays and cell proliferation assays of various human lung cancer cell lines (nanomolar concentration causing $50 \%$ inhibition (adapted from Solca et al. and Li et al. $[59,61])$

\begin{tabular}{|c|c|c|c|c|c|}
\hline & $\mathrm{EGFR}^{\mathrm{WT}}$ & $\mathrm{EGFR}^{\mathrm{L} 858 \mathrm{R}}$ & $\mathrm{EGFR}^{\mathrm{L} 858 \mathrm{R} / \mathrm{T} 790 \mathrm{M}}$ & HER2 & HER4 \\
\hline \multicolumn{6}{|c|}{ Cell-free kinase assays } \\
\hline Afatinib & $0.2-0.7$ & $0.2-0.4$ & $9-10$ & $7-25$ & $0.7-1.7$ \\
\hline Erlotinib & $0.9-1.7$ & $1.1-2.7$ & $1520-3562$ & $238-698$ & $579-756$ \\
\hline Gefitinib & $0.4-4.7$ & $0.8-1.4$ & $534-1267$ & $416-1830$ & $293-323$ \\
\hline \multicolumn{6}{|c|}{ Cell proliferation assays } \\
\hline Afatinib & 60 & 0.7 & $92-225$ & $12-56$ & NA \\
\hline Erlotinib & 110 & 40 & $>4000$ & $>4000$ & NA \\
\hline Gefitinib & 157 & 5 & $>4000$ & $>4000$ & NA \\
\hline
\end{tabular}

EGFR epidermal growth factor receptor, HER2 human epidermal growth factor receptor 2 (ErbB2), WT wild-type, $N A$ not available 
Table 3 Patient-reported outcome assessments in first-line EGFR mutation-positive clinical trials

\begin{tabular}{|c|c|c|c|c|}
\hline Trial & Treatments & $\begin{array}{l}\text { QoL } \\
\text { assessments }\end{array}$ & Methodology & Outcomes \\
\hline $\begin{array}{c}\text { IPASS } \\
{[20]}\end{array}$ & $\begin{array}{l}\text { Gefitinib vs. } \\
\text { carboplatin }+ \text { paclitaxel }\end{array}$ & $\begin{array}{r}\text { FACT-L and } \\
\text { FACT-TOI }\end{array}$ & $\begin{array}{l}\text { Randomization, week } 1 \text {, every } 3 \text { weeks } \\
\text { until day } 127 \text {, once every } 6 \text { weeks from } \\
\text { day } 128 \text { until disease progression, and } \\
\text { when the study drug was discontinued }\end{array}$ & $\begin{array}{l}\text { Significantly more pts in the gefitinib } \\
\text { group than in the } \\
\text { carboplatin }+ \text { paclitaxel group had a } \\
\text { clinically relevant improvement in } \\
\text { QoL and by scores on the FACT-TOI. } \\
\text { Rates of reduction in symptoms were } \\
\text { similar }\end{array}$ \\
\hline $\begin{array}{l}\text { EURTAC } \\
{[21]}\end{array}$ & $\begin{array}{l}\text { Erlotinib vs. } \\
\text { cisplatin }+ \text { docetaxel or } \\
\text { gemcitabine }\end{array}$ & $\begin{array}{l}\text { Completion } \\
\text { of the lung } \\
\text { cancer } \\
\text { symptom } \\
\text { scale }\end{array}$ & $\begin{array}{l}\text { Baseline, every } 3 \text { weeks, end-of-treatment } \\
\text { visit and every } 3 \text { months during follow- } \\
\text { up }\end{array}$ & $\begin{array}{l}\text { Insufficient data collected for any } \\
\text { analysis to be done, due to low } \\
\text { compliance }\end{array}$ \\
\hline $\begin{array}{l}\text { LL3 [66, } \\
\quad 70]\end{array}$ & $\begin{array}{l}\text { Afatinib vs. } \\
\text { cisplatin }+ \text { pemetrexed }\end{array}$ & $\begin{array}{l}\text { EORTC } \\
\text { QLQ-C30, } \\
\text { EORTC } \\
\text { QLQ-LC13 }\end{array}$ & $\begin{array}{l}\text { Baseline, every } 3 \text { weeks until disease } \\
\text { progression }\end{array}$ & $\begin{array}{l}\text { Afatinib improved lung cancer-related } \\
\text { symptoms and QoL, and delay of } \\
\text { deterioration of symptoms vs. } \\
\text { chemotherapy }\end{array}$ \\
\hline LL6 [67] & $\begin{array}{l}\text { Afatinib vs. } \\
\text { gemcitabine }+ \text { cisplatin }\end{array}$ & $\begin{array}{l}\text { EORTC } \\
\text { QLQ-C30, } \\
\text { EORTC } \\
\text { QLQ-LC13 }\end{array}$ & $\begin{array}{l}\text { Baseline, every } 3 \text { weeks until disease } \\
\text { progression }\end{array}$ & $\begin{array}{l}\text { Afatinib improved lung cancer-related } \\
\text { symptoms of cough, dyspnea, and } \\
\text { pain, and global health status/QoL vs. } \\
\text { chemotherapy }\end{array}$ \\
\hline
\end{tabular}

EGFR epidermal growth factor receptor, EORTC-QLQ European Organization for Research and Treatment of Cancer Quality of Life Questionnaire, FACT-L Functional Assessment of Cancer Therapy - Lung, FACT-TOI Functional Assessment of Cancer Therapy - Trial Outcome Index, $Q L Q-L C 13$ Quality of Life Questionnaire - Lung Cancer Module, $Q o L$ quality of life

was restricted to patients with common EGFR mutations only, the PFS advantage over chemotherapy was more pronounced. The PFS benefit versus chemotherapy conferred by afatinib, gefitinib, and erlotinib in phase III trials is summarized in Table 1 . In the context of previous studies with erlotinib and gefitinib, the median PFS values of 13.6 and 11.0 months achieved with afatinib appear favorable. However, a number of recent meta-analyses have failed to detect any significant differences in efficacy between afatinib and first-generation TKIs [71-73], emphasizing the need for head-to-head data. Nevertheless, a recently published network meta-analysis showed an estimated probability of being best for afatinib over all other treatments for PFS of 70 versus $27 \%$ for erlotinib and $3 \%$ for gefitinib [74].

Interestingly, afatinib also appears to be active in a subset of patients with certain uncommon EGFR mutations. In a pooled analysis of LL3, LL6, and the phase II LL2 study [75], patients with rare mutations/duplications in exons $18-21(n=38)$ who received afatinib had a median PFS of 10.7 months [76]. However, for 14 patients with de novo $T 790 M$ mutations, outcomes were variable but generally poor. In these patients, the response rate was $14.3 \%$, median PFS was 2.9 months, and OS was 14.9 months [76]. Given the small sample size, these data should be interpreted with caution. However, it may be that chemotherapy may be the most appropriate treatment option in patients with de novo T790M mutations.
Nevertheless, given that afatinib shows preclinical activity against $T 790 M$ in vitro and in vivo, further studies are warranted in patients with $T 790 M$-positive tumors. One ongoing study, for example, is examining the feasibility of intermittent high-dose afatinib in such patients (NCT01647711). In LL3, LL6, and LL2, outcomes were also poor against tumors harboring exon 20 insertions (median PFS 2.7 months, $n=23$ ).

Another sub-analysis (of the LL3 study) indicated that afatinib is also beneficial in patients with brain metastases [77]. In this subgroup $(n=35)$, median PFS with afatinib versus chemotherapy was 11.1 vs. 5.4 months (HR 0.52 [95\% CI 0.22-1.23; $p=0.13]$ ). Among patients with intracranial progression $(n=10)$, median time to progression was 11.6 months with afatinib versus 5.5 months with chemotherapy [77]. Furthermore, a compassionate use program indicated that afatinib had clinical activity in NSCLC patients with central nervous system metastases who had progressed on chemotherapy and an EGFR-TKI [78]. Further analyses of afatinib in NSCLC patients harboring uncommon EGFR mutations or with brain metastases are ongoing.

\subsection{Key Secondary Endpoint: Overall Survival}

Median follow-up for OS was 41 and 33 months in LL3 and LL6, respectively [68]. In the overall dataset (all EGFR mutations), no significant difference in median OS was 
A

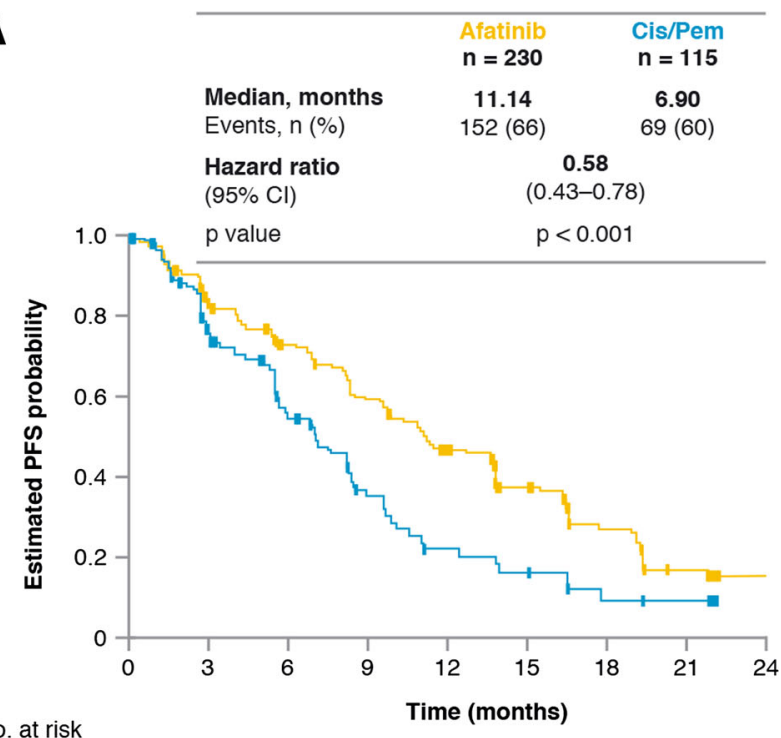

$\begin{array}{lrrrrrrrrr}\text { Afatinib } & 230 & 180 & 151 & 120 & 77 & 50 & 31 & 10 & 3 \\ & & 715 & 41 & 21 & 11 & 7 & 3 & 2 & 0\end{array}$

B

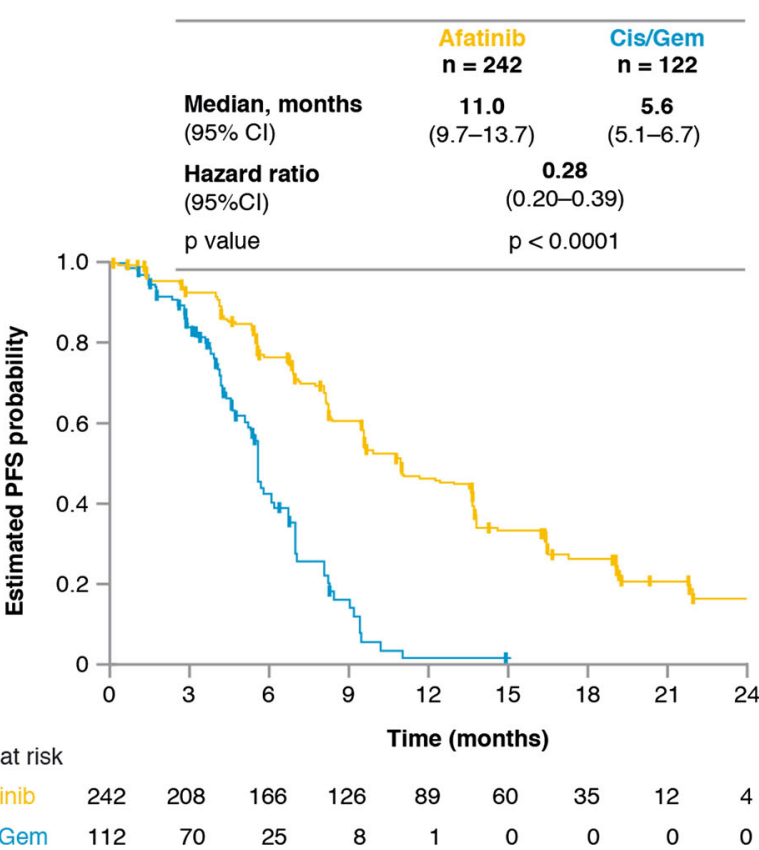

Fig. 2 Progression-free survival for afatinib versus chemotherapy in a Lux-Lung 3 [66] and b Lux-Lung 6 [67]. a Sequist, LV et al: J Clin Oncol 31 (27), 2013: 3327-34. Reprinted with permission. (C) (2013) American Society of Clinical Oncology. All rights reserved. b Reprinted from The Lancet Oncology, Vol. 15, Wu YL et al, Afatinib versus cisplatin plus gemcitabine for first-line treatment of Asian patients with advanced non-small-cell lung cancer harbouring EGFR mutations (LUX-Lung 6): an open-label, randomised phase 3 trial, pp. 213-22, 2014, with permission from Elsevier. CI confidence interval, Cis/Gem cisplatin/gemcitabine, Cis/Pem cisplatin/pemetrexed, $P F S$ progression-free survival

observed between the afatinib and chemotherapy arms (LL3 28.2 vs. 28.2 months; HR 0.88 [95 \% CI 0.66-1.17; $p=0.39$ ]; LL6 23.1 vs. 23.5 months; HR 0.93 [95\% CI
$0.72-1.22 ; p=0.61])$. Interestingly, in a prespecified analysis, median OS was significantly improved with afatinib compared with chemotherapy in patients harboring Del19 mutations in both LL3 (33.3 vs. 21.1 months; HR 0.54 [95 \% CI 0.36-0.79; $p=0.0015]$ ) and LL6 (31.4 vs. 18.4 months; HR 0.64 [95 \% CI 0.44-0.94; $p=0.0229$ ]; Table 1; Fig. 3a/b); no OS difference was observed in the L858R mutation-positive subgroup. However, in a prespecified analysis of median OS in patients with common mutations (Del19/L858R), a trend towards OS benefit was observed (LL3 31.6 vs. 28.2 months; HR 0.78 [95\% CI $0.58-1.06 ; \mathrm{p}=0.11]$; LL6 23.6 vs. 23.5 months; HR 0.83 [95\% CI $0.62-1.09 ; p=0.18]$; Table 1). Afatinib is the first agent to demonstrate improved OS versus standard-ofcare platinum-doublet chemotherapy in a molecularly-defined population of patients with NSCLC. No head-to-head studies are currently available to allow direct comparison of OS achieved with afatinib versus first-generation EGFRTKIs. However, a phase IIb trial comparing first-line afatinib versus gefitinib with EGFR mutation-positive lung adenocarcinoma is ongoing (NCT01466660).

While the majority of patients in LL3, and all patients in LL6, were Asian, the OS benefit with afatinib over chemotherapy in patients harboring the EGFR Del19 mutation was independent of ethnicity; OS in non-Asian patients $(n=46)$ was 33.6 vs. 20.0 months (HR 0.45 [95\% CI 0.21-0.95; $p=0.03$ ]) [68]; OS in Asian patients (LL3 and LL6 combined; $n=309$ ) was 31.7 vs. 21.1 months (HR 0.61 [95\% CI $0.46-0.82 ; p<0.01]$ ) [79]. Furthermore, a significant OS improvement with afatinib versus chemotherapy in patients harboring the Del19 mutation was observed in the Chinese subgroup of LL6 ( $n=166 ; 31.6$ vs. 16.3 months; HR 0.61 [95\% CI $0.41-0.91 ; p=0.015])$ and in the Japanese subgroup of LL3 ( $n=39 ; 46.9$ vs. 31.5 months; HR 0.34 [95\% CI $0.13-0.87 ; p=0.018]$ ] $[80,81]$. The more pronounced OS benefit observed with afatinib in Japanese patients may reflect greater access to subsequent therapies following disease progression [68]. These subgroup data support the applicability of the OS findings in LL3 and LL6 to all patients with EGFR mutation-positive disease, regardless of race/ethnicity.

In contrast to afatinib, neither erlotinib nor gefitinib demonstrated an OS benefit versus chemotherapy in patients harboring Del19 or, indeed, L858R mutation-positive disease $[21,26,28]$. The lack of OS benefit with gefitinib or erlotinib versus chemotherapy, either in total datasets or in patients with the EGFR Del19 mutation (Table 1) [17, 25-30], has been attributed, at least partially, to post-progression therapy with EGFR-TKIs in patients initially randomized to chemotherapy [17, 25-27, 29, 30]. In this context, it is interesting to note that crossover rates in LL3 and LL6 were similar to those in phase III trials 


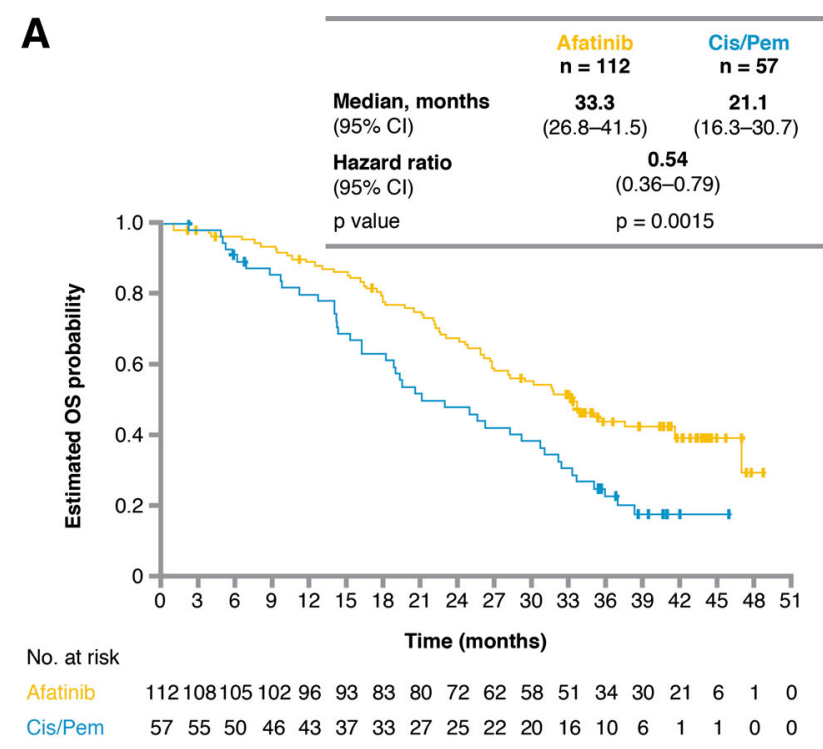

B

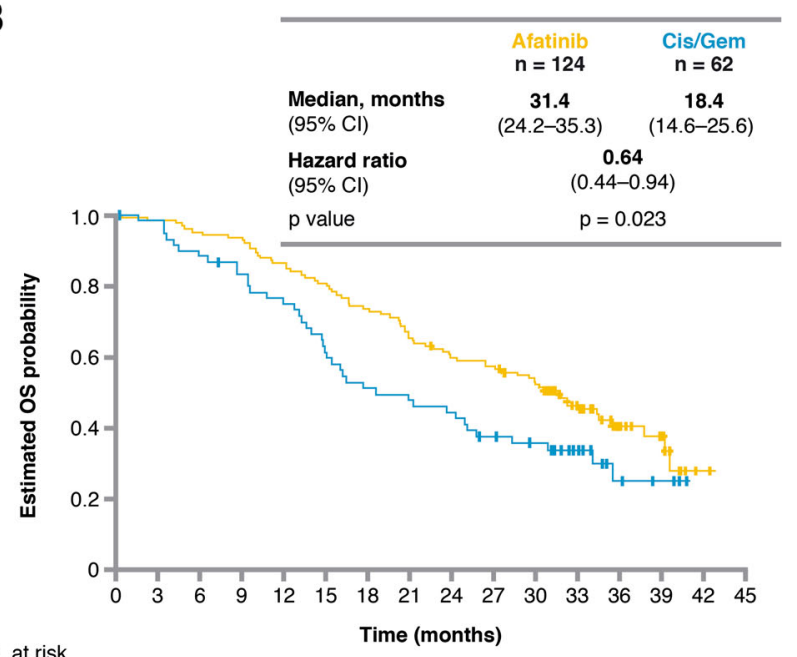

No. at risk

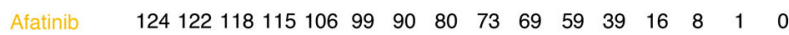

$\begin{array}{lllllllllllllllll}\mathrm{Cis} / \mathrm{Gem} & 62 & 58 & 53 & 49 & 44 & 35 & 30 & 28 & 26 & 21 & 18 & 11 & 4 & 3 & 0 & 0\end{array}$

Fig. 3 Overall survival in patients with exon 19 deletions in LUXLung 3 and LUX-Lung 6 [68]. Reprinted from The Lancet Oncology, Vol. 16, Yang JC et al, Afatinib versus cisplatin-based chemotherapy for EGFR mutation-positive lung adenocarcinoma (LUX-Lung 3 and LUX-Lung 6): analysis of overall survival data from two randomised, phase 3 trials, pp. 141-51, 2015, with permission from Elsevier. $C I$ confidence interval, $\mathrm{Cis} / \mathrm{Gem}$ cisplatin/gemcitabine, Cis/Pem cisplatin/pemetrexed, $O S$ overall survival

with gefitinib or erlotinib in this setting [21, 23, 25-27]. Furthermore, in LL3, a significant OS benefit with afatinib versus chemotherapy was observed in Japanese patients despite the fact that nearly all chemotherapy-treated patients in this sub-analysis received an EGFR-TKI following disease progression [80].

Taken together, OS analyses in LL3 and LL6 indicate that afatinib should be considered as a first-line therapy for patients with EGFR Del19 mutation-positive lung adenocarcinoma [82], and is also a valuable option for patients with EGFR mutation-positive NSCLC harboring other common mutations ( $L 858 R)$ as well as a subset of patients with certain uncommon mutations. The significantly and substantially longer OS achieved by afatinib in Del19 patients further suggests that patients with EGFR Del19 and L858R mutation-positive disease should be studied separately in future trials evaluating TKIs in patients with EGFR mutation-positive NSCLC.

\subsection{Patient-Reported Outcomes}

Disease-related symptoms, treatment-related adverse events (AEs), and treatment efficacy all substantially influence patients' QoL [83]. In order to assess the effect of afatinib on QoL, both LL3 and LL6 fully integrated comprehensive PRO evaluation into outcome analyses (Table 3). In contrast with IPASS (which utilized Functional Assessment of Cancer Therapy indices) and EURTAC (where insufficient PRO data were collected for analysis), the afatinib trials assessed both EORTC QLQLC13 and QLQ-C30. This provided a complete picture of both lung cancer-related symptoms and symptoms related to treatment. These analyses demonstrated that afatinib improved prespecified lung cancer-related symptoms (cough, dyspnea, and pain) and delayed their deterioration versus chemotherapy. In LL3, afatinib significantly delayed time to deterioration for cough $(p=0.007)$ and dyspnea $(p=0.015)$, but not pain $(p=0.19)$, and was associated with improved mean scores over time for cough and dyspnea (both $p<0.001$ ). Improvements in mean scores over time were also observed with afatinib versus chemotherapy for functional health status/QoL $(p=0.015)$ and physical $(p<0.001)$, role $(p=0.004)$, and cognitive ( $p=0.007$ ) functioning $[66,70]$. In LL6, afatinib significantly delayed time to deterioration for cough $(p<0.0001)$, dyspnea $(p<0.0001)$, and pain $(p=0.027)$ versus chemotherapy, and was associated with improvements in mean scores over time for each symptom (all $p<0.0001)$. Furthermore, more patients treated with afatinib versus chemotherapy showed longer time to deterioration $(p=0.0002)$, better mean scores over time $(p<0.0001)$, and improvements from baseline in global health status/QoL $(p<0.0001)$ [67].

\subsection{Safety/Tolerability}

In both LL3 and LL6, afatinib was associated with predictable and manageable AE profiles, and low discontinuation rates due to treatment-related AEs. In LL3, grade 3 or higher treatment-related AEs occurred in 112 (49\%) patients receiving afatinib and $53(48 \%)$ patients receiving chemotherapy [66]. The most common treatment-related AEs (all grades/grade 3 or higher) were diarrhea (95/14 \%) 
rash/acne $(89 / 16 \%)$, stomatitis/mucositis $(72 / 9 \%)$, and paronychia $(57 / 11 \%)$ in the afatinib arm and nausea (66/ $4 \%$ ), decreased appetite $(53 / 3 \%)$, fatigue $(47 / 13 \%)$, and vomiting $(42 / 3 \%)$ in the chemotherapy arm. Therapy was discontinued because of treatment-related AEs in $8 \%$ of those receiving afatinib and $12 \%$ of those receiving chemotherapy. Of the most common AEs associated with afatinib, only diarrhea $(1.3 \%)$ and paronychia (0.9\%) resulted in treatment discontinuation. In LL6, treatmentrelated AEs grade 3 or higher occurred in 86 (36\%) patients receiving afatinib and $68(60 \%)$ patients receiving chemotherapy [67]. As with LL3, the most common treatment-related AEs (all grades/grade 3 or higher) were diarrhea $(88 / 5 \%)$, rash/acne $(81 / 15 \%)$, stomatitis/mucositis $(52 / 5 \%)$, and paronychia $(33 / 0 \%)$ in the afatinib arm and vomiting $(81 / 19 \%)$, nausea $(75 / 8 \%)$, decreased appetite $(41 / 2 \%)$, and fatigue $(36 / 1 \%)$ in the chemotherapy arm. Therapy was discontinued because of treatmentrelated AEs in $6 \%$ of patients receiving afatinib and $40 \%$ of patients receiving chemotherapy. The most common cause of discontinuation in the afatinib arm was rash/acne $(2 \%)$. No patients discontinued due to diarrhea only.

\subsection{Adverse Event Management}

In general, drug-related AEs were effectively managed with supportive care and/or protocol-defined dose reductions and led to few treatment-related discontinuations [66, 67]. Of note, afatinib-treated patients were permitted to dose-escalate from the initial $40 \mathrm{mg}$ dose to $50 \mathrm{mg} / \mathrm{day}$ after the first 21-day treatment cycle if no drug-related AEs higher than grade 1 were experienced, while dose reductions in $10 \mathrm{mg}$ decrements to a minimum final dose of $20 \mathrm{mg}$ were recommended for patients experiencing drugrelated grade 3 or selected prolonged grade 2 AEs [66, 67]. This active management of AEs associated with afatinib facilitates treatment compliance and improvements in PROs, and allows patients to achieve maximum therapeutic benefit with this agent $[84,85]$.

In LL3, pharmacokinetic assessments demonstrated similar geometric mean plasma concentrations of afatinib for all permitted dose groups $(20,30,40$, and $50 \mathrm{mg})$ after tolerability-guided dose adjustments [66]. Importantly, protocol-defined dose reductions based on individual patient AEs were shown to reduce excessive plasma concentrations of afatinib, thereby optimizing patient exposure to the active drug as well as managing tolerability without compromising efficacy [66].

\subsection{Summary}

In two large phase III trials, afatinib demonstrated OS benefit versus chemotherapy in patients harboring Del19 mutations, the most common $E G F R$ aberration in patients with NSCLC. Based on these observations, some commentators have concluded that afatinib should be considered as a first-line therapy for patients with $E G F R$ Del19 mutation-positive lung adenocarcinoma [68, 82]. Although no significant difference in OS was observed in patients harboring the $L 858 R$ mutation, significant improvements over chemotherapy in PFS and PROs of disease-related symptoms and QoL, as well as a predictable and manageable safety profile in all patients with EGFR mutation-positive NSCLC, including the L858R mutation, suggest an important clinical benefit with afatinib in patients with EGFR mutation-positive disease [66-68].

\section{Clinical Trials of Afatinib in the Relapsed/ Refractory Setting in Patients with NSCLC}

\subsection{LUX-Lung 1 (LL1)}

In this phase IIb/III trial, afatinib monotherapy $(50 \mathrm{mg} /$ day) was evaluated versus placebo in patients $(n=585)$ with stage IIIb or IV lung adenocarcinoma following failure of up to two lines of chemotherapy and $\geq 12$ weeks of erlotinib and/or gefitinib [86, 87]. The primary endpoint was OS; secondary endpoints included PFS and OR; health-related QoL was also assessed.

A positive test for $E G F R$ mutation status was not required for enrollment; however, the $E G F R$ mutation status of 141 patients was known, and $68 \%$ of these patients had activating EGFR mutations. Clinical endpoints were assessed in a subpopulation of patients who were clinically enriched for EGFR mutations based on Jackman criteria [88], i.e. patients with a known EGFR-activating mutation plus patients who had achieved an OR or durable stable disease (SD) for $>6$ months, followed by systemic disease progression of disease, on continuous gefitinib/erlotinib treatment.

A significant improvement in median PFS was observed with afatinib over placebo ( 3.3 vs. 1.1 months; HR 0.38 [95\% CI 0.31-0.48; $p<0.0001]$ ] [86]. In a subgroup analysis of patients who met Jackman criteria of acquired resistance $(n=214)$, median PFS was 4.5 versus 1.0 months in the afatinib and placebo arms, respectively (HR 0.37 [95\% CI 0.26-0.52]). The prolongation of PFS observed with afatinib was associated with improvements in lung cancer-related symptoms, with a significantly higher proportion of patients having improvements in disease-related cough $(p<0.0001)$, dyspnea $(p=0.006)$, and pain $(p<0.0001)$ [87]. Improvements in EORTC global health status, physical functioning, and fatigue were also observed with afatinib (all $p<0.05$ ). 
Median OS was not significantly different with afatinib versus placebo (10.8 vs. 12.0 months; HR 1.08 [95 \% CI $0.86-1.35 ; p=0.74])$. However, of note, more patients in the placebo group (79 \%) than in the afatinib group (68\%) received subsequent anticancer therapies following discontinuation of study medication, including EGFR-TKIs, which potentially confounded the OS results. No complete responses (CRs) were noted in either arm; partial responses (PRs) were observed in 29 (7\%) patients in the afatinib group and one $(<1 \%)$ patient in the placebo group. Afatinib was associated with a manageable safety profile. Diarrhea $(17 \%)$ and rash/acne $(14 \%)$ were the most common grade 3 AEs; however, these events led to few treatment discontinuations (3.6 and $1.8 \%$, respectively) [86].

Although no OS benefit was observed with afatinib over placebo in LL1, improvements in PFS, tumor response, and PROs of disease-related symptoms with afatinib suggested that this agent could potentially be of benefit to patients with advanced NSCLC who had failed previous EGFRTKI therapy.

\subsection{LUX-Lung 5 (LL5)}

The phase III LL5 trial evaluated the efficacy and safety of continued irreversible ErbB family blockade with afatinib combined with paclitaxel versus investigator's choice of chemotherapy alone in patients with NSCLC who had acquired resistance to prior erlotinib/gefitinib and afatinib monotherapy [89]. The study was conducted over two stages.

In part A, patients who had failed one or more line of chemotherapy and erlotinib/gefitinib (after $\geq 12$ weeks of treatment) were treated with afatinib monotherapy (50 mg/day). In part $\mathrm{B}$, patients achieving $\geq 12$ weeks of benefit (CR/PR/SD) with afatinib monotherapy $(n=202)$ were randomized $2: 1$ to receive afatinib plus paclitaxel (40 mg/day; $80 \mathrm{mg} / \mathrm{m}^{2} /$ week) or physician's choice of single-agent chemotherapy. The primary endpoint was PFS; other endpoints included objective response rate (ORR), OS, safety, and PROs.

Significant improvements in median PFS (5.6 vs. 2.8 months; HR 0.60 [95 \% CI 0.43-0.85; $p=0.003]$ ) and ORR (32.1 vs. 13.2\%; HR 3.41 [95 \% CI 1.41-6.79; $p=0.005])$ were observed with afatinib plus paclitaxel compared with chemotherapy alone [89]. However, there was no significant difference in OS (12.2 vs. 12.2 months; HR 1.00 [95 \% CI 0.70-1.43; $p=0.994]$ ); this could reflect differences in post-progression treatment between arms. Patients had received at least four lines of therapy at randomization to afatinib plus paclitaxel or chemotherapy, and approximately $60 \%$ of patients received at least one subsequent therapy post-progression. More patients in the chemotherapy arm received two additional lines of therapy than in the afatinib plus paclitaxel arm (36 vs. $15 \%$ ).

There was a trend towards delayed time to deterioration of dyspnea (3.1 vs. 1.8 months; HR $0.78 \quad$ [95\% CI $0.55-1.09 ; p=0.144])$ and pain (4.3 vs. 3.5 months; HR 0.80 [95\% CI $0.56-1.14 ; p=0.212])$ but not cough $(5.7$ vs. 6.5 months; HR 1.13 [95 \% CI 0.79-1.62; $p=0.505]$ ) in patients receiving paclitaxel versus chemotherapy [90]. There was also a trend towards an increased proportion of patients with improvements in dyspnea (45 vs. $35 \%$; $p=0.222$ ) and cough (46 vs. $36 \% ; p=0.225)$ in patients receiving afatinib plus paclitaxel; differences in mean scores over time also favored afatinib plus paclitaxel for dyspnea $(-2.9 ; p=0.191)$ and cough $(-3.8 ; p=0.201)$. Afatinib plus paclitaxel had a manageable AE profile; treatment-related AEs were consistent with those previously reported for each agent, with (all grades) diarrhea (53.8 vs. $6.7 \%)$, alopecia (32.6 vs. $15.0 \%$ ), and asthenia (27.3 vs. $28.3 \%$ ) as the most common treatment-related AEs observed with afatinib plus paclitaxel versus chemotherapy [89]. This manageable AE profile and QoL maintenance was observed despite the prolonged exposure to afatinib plus paclitaxel (median 133 days) compared with chemotherapy (median 51 days).

In summary, LL5 is the first randomized trial to demonstrate prospective evidence/proof of concept for maintaining irreversible ErbB family inhibition beyond disease progression in oncogene-addicted lung cancer. Overall, these findings support the hypothesis that tumors progressing on erlotinib/gefitinib and afatinib continue to depend on ErbB family receptor signaling and can benefit from continuous ErbB family blockade with afatinib. Interestingly, it was recently reported that gefitinib postprogression (combined with cisplatin + pemetrexed) did not confer any clinical benefit versus chemotherapy alone in patients with confirmed activating EGFR mutations progressing after first-line gefitinib monotherapy [91].

\section{Afatinib in Combination Regimens}

\subsection{Rationale}

The pharmacokinetic properties of afatinib are conducive to the development of novel combination regimens with other drugs. Afatinib is an orally bioavailable agent that achieves peak plasma concentrations $\sim 2-5 \mathrm{~h}$ after dosing $[92,93]$. Due to its high solubility ( $\mathrm{pH}$ range $1.0-7.5$ ), interactions with acid-reducing drugs are not expected. Unlike the reversible EGFR-TKIs erlotinib and gefitinib, oxidative and cytochrome P450 (CYP) enzyme-dependent metabolism are of negligible importance for afatinib; thus, the potential for interaction with other agents that are either 
metabolized by, or are inhibitors or inducers of, CYP-related enzymes, is low $[92,94]$. This overall low probability of drug-drug interactions makes afatinib an attractive combination partner for chemotherapies and other targeted therapies. In this context, a substantial number of clinical studies aimed to identify potential combination partners and patients who may benefit from particular combination therapies have been undertaken or are ongoing (e.g. NCT01999985, NCT02191891, NCT01861223) [95-103].

\subsection{Dual Inhibition of EGFR with Afatinib and Cetuximab in TKI-Resistant EGFR-Mutant Lung Cancer with and without T790M Mutations}

In a recent phase Ib study, afatinib combined with the antiEGFR monoclonal antibody, cetuximab, has demonstrated promising activity in patients who had failed on erlotinib or gefitinib [104]. In 126 patients treated with the MTD of afatinib plus cetuximab, the confirmed OR rate was $29 \%$; interestingly, the response rate was similar in patients harboring $T 790 M$-positive and $T 790 M$-negative tumors (32 vs. $25 \% ; p=0.341)$. The mode of action for the observed clinical efficacy is currently unknown. It could be related to the fact that the tumor cells remain dependent on ErbB signaling (due to acquired EGFR mutations, EGFR amplification, and/or HER2 amplification); as such, simultaneous vertical inhibition of the intracellular domain of the ErbB receptors with afatinib and the extracellular domain of EGFR with cetuximab might result in increased efficacy compared with monotherapy with either agent [104].

These preliminary data are encouraging given that no approved treatment options are currently available for patients with acquired resistance to first-generation inhibitors. In this context, findings from phase I dose-escalation trials of third-generation EGFR inhibitors (designed to bind with higher affinity to EGFR harboring $T 790 M$ ), including AZD-9291, CO-1686, and HM-61713, are also promising. These studies reported $>50 \%$ response rates in patients with EGFR T790M-positive NSCLC who had failed previous first-generation EGFR-TKI therapy [105-107].

\section{Second-Line Treatment for Patients with Squamous Cell Carcinoma of the Lung: LUX-Lung 8 (LL8)}

Squamous histology represents approximately $30 \%$ of NSCLC [108], and there is a major unmet need for effective treatments in patients with squamous cell carcinoma (SCC) of the lung. Targetable oncogenic alterations are limited and have not yet translated to a therapeutic paradigm. Despite the fact that $E G F R$ mutations are rare in tumors with squamous cell histology $(<5 \%)$ [109], afatinib has shown encouraging activity in such tumor types, including a subset of patients with SCC in LL5 [110] and SCC of the head and neck [111]. This may reflect the observation that SCCs often overexpress EGFR [112-114]. Furthermore, other ErbB receptors or their cognate ligands have been shown to be overexpressed, amplified, or mutated in patients with SCC of the lung [115-117].

LL8 is the first phase III trial to prospectively compare second-line EGFR-TKIs in patients with SCC of the lung [118]. In this global study, patients $(n=795)$ with relapsed/refractory stage IIIb/IV SCC were randomized 1:1 to receive afatinib $(40 \mathrm{mg} /$ day $)$ or erlotinib $(150 \mathrm{mg} /$ day $)$. Patients recruited to this trial had progressed after four or more cycles of platinum-based doublet chemotherapy and had not received prior EGFR-TKI therapy. The primary endpoint was PFS as assessed by independent radiological review (IRR). Secondary endpoints included OS, ORR, disease control rate (DCR), PROs, and safety. A significant improvement in median PFS was observed with afatinib versus erlotinib (2.6 vs. 1.9 months; HR 0.81 [95\% CI $0.69-0.96 ; p=0.010]$ ) [118]. Notably, given the paucity of second-line treatment options in patients with SCC of the lung, afatinib significantly improved OS versus erlotinib (7.9 vs. 6.8 months; HR 0.81 [95\% CI 0.69-0.95; $p=0.008]$ ] [118]. DCR was significantly higher with afatinib versus erlotinib (50.5 vs. $39.5 \% ; p=0.002)$; ORR was $5.5 \%$ with afatinib and $2.8 \%$ with erlotinib $(p=0.055)$.

The overall AE profile for afatinib and erlotinib was comparable, with grade 3 or higher AEs reported in 57.1 and $57.5 \%$ of patients, respectively. A higher incidence of drug-related grade 3 or higher diarrhea (10.4 vs. $2.6 \%$ ) and grade 3 stomatitis ( 4.1 vs. $0.0 \%$ ) was observed with afatinib, and a higher incidence of grade $3 \mathrm{rash} / \mathrm{acne}$ was observed with erlotinib (5.9 vs. $10.4 \%$ ) [118]. Furthermore, more patients in the afatinib arm reported improved global health status/QoL (35.7 vs. $28.3 \% ; p=0.041)$ and cough (43.4 vs. $35.2 \% ; p=0.029)$ versus erlotinib. Taken together, these findings indicate that afatinib provides a significant improvement in PFS, OS, and DCR versus erlotinib, with a predictable and manageable AE profile, consistent with the mechanistic profile of EGFR inhibition, in patients with relapsed/refractory SCC.

\section{Conclusions}

In patients with advanced EGFR mutation-positive NSCLC, first-line afatinib significantly improved PFS, PROs, and QoL versus standard-of-care platinum-doublet chemotherapy regimens in two large phase III studies. In 
addition, afatinib demonstrated a significant OS advantage versus chemotherapy in patients with NSCLC harboring EGFR Del19 mutations. These findings suggest that afatinib could be considered the preferred first-line treatment option for NSCLC patients with EGFR Del19 mutations, although head-to-head data will be helpful to confirm this assertion. Furthermore, the improvements in PFS and PROs observed with afatinib regardless of mutation type indicate that important clinical benefits are achieved with afatinib in all patients with common EGFR mutation-positive NSCLC. Afatinib has also demonstrated promising activity in patients who have failed on erlotinib and gefitinib and in patients with active brain metastases. In patients with SCC of the lung who have failed on first-line chemotherapy, afatinib significantly improved PFS, OS, and DCR versus erlotinib. Several clinical studies are currently ongoing that will help further define the role of afatinib in a relapsed/refractory setting.

Acknowledgments Medical writing support, supported financially by Boehringer Ingelheim, was provided by Shaun Villa and Lynn Pritchard of GeoMed, an Ashfield company, part of UDG Healthcare plc, prior to submission of this article.

Author contribution Vera Hirsh was responsible for the conception and development of this invited review article, critically revised the content of the manuscript at all stages and provided final approval of the submitted version. Vera Hirsh is the guarantor for the overall content.

Disclosure Vera Hirsh has received honoraria from Boehringer Ingelheim for participation in advisory boards

Open Access This article is distributed under the terms of the Creative Commons Attribution-NonCommercial 4.0 International License (http://creativecommons.org/licenses/by-nc/4.0/), which permits any noncommercial use, distribution, and reproduction in any medium, provided you give appropriate credit to the original author(s) and the source, provide a link to the Creative Commons license, and indicate if changes were made.

\section{References}

1. Saintigny P, Burger JA. Recent advances in non-small cell lung cancer biology and clinical management. Discov Med. 2012;13(71):287-97.

2. National Comprehensive Cancer Network. NCCN Clinical Practice Guidelines in Oncology—Non Small Cell Lung Cancer, Version 3.2014. 2014. http://www.nccn.org/professionals/ physician_gls/pdf/nscl.pdf. Accessed 4 March 2014.

3. Leighl NB. Treatment paradigms for patients with metastatic non-small-cell lung cancer: first-, second-, and third-line. Curr Oncol. 2012;19(Suppl. 1):S52-8.

4. Hanna N, Shepherd FA, Fossella FV, et al. Randomized phase III trial of pemetrexed versus docetaxel in patients with nonsmall-cell lung cancer previously treated with chemotherapy. J Clin Oncol. 2004;22(9):1589-97.
5. Shepherd FA, Dancey J, Ramlau R, et al. Prospective randomized trial of docetaxel versus best supportive care in patients with non-small-cell lung cancer previously treated with platinum-based chemotherapy. J Clin Oncol. 2000;18(10): 2095-103.

6. Shepherd FA, Rodrigues Pereira J, Ciuleanu T, et al. Erlotinib in previously treated non-small-cell lung cancer. N Engl J Med. 2005;353(2):123-32.

7. Thatcher N, Chang A, Parikh P, et al. Gefitinib plus best supportive care in previously treated patients with refractory advanced non-small-cell lung cancer: results from a randomised, placebo-controlled, multicentre study (Iressa Survival Evaluation in Lung Cancer). Lancet. 2005;366(9496):1527-37.

8. Kim ES, Hirsh V, Mok T, et al. Gefitinib versus docetaxel in previously treated non-small-cell lung cancer (INTEREST): a randomised phase III trial. Lancet. 2008;372(9652):1809-18.

9. Zer A, Leighl N. Promising targets and current clinical trials in metastatic non-squamous NSCLC. Front Oncol. 2014;4:329.

10. Solomon B, Wilner KD, Shaw AT. Current status of targeted therapy for anaplastic lymphoma kinase-rearranged non-small cell lung cancer. Clin Pharmacol Ther. 2014;95(1):15-23.

11. Yap TA, Popat S. Toward precision medicine with next-generation EGFR inhibitors in non-small-cell lung cancer. Pharmgenomics Pers Med. 2014;7:285-95.

12. Roskoski R Jr. The ErbB/HER family of protein-tyrosine kinases and cancer. Pharmacol Res. 2014;79:34-74.

13. Yarden Y, Pines G. The ERBB network: at last, cancer therapy meets systems biology. Nat Rev Cancer. 2012;12(8):553-63.

14. Chan BA, Hughes BG. Targeted therapy for non-small cell lung cancer: current standards and the promise of the future. Transl Lung Cancer Res. 2015;4(1):36-54.

15. Reguart N, Remon J. Common EGFR-mutated subgroups (Del19/L858R) in advanced non-small-cell lung cancer: chasing better outcomes with tyrosine-kinase inhibitors. Future Oncol. 2015;11(8):1245-57.

16. Engelman JA, Janne PA. Mechanisms of acquired resistance to epidermal growth factor receptor tyrosine kinase inhibitors in non-small cell lung cancer. Clin Cancer Res. 2008;14(10): 2895-9.

17. Han JY, Park K, Kim SW, et al. First-SIGNAL: first-line singleagent iressa versus gemcitabine and cisplatin trial in neversmokers with adenocarcinoma of the lung. J Clin Oncol. 2012;30(10):1122-8.

18. Maemondo M, Inoue A, Kobayashi K, et al. Gefitinib or chemotherapy for non-small-cell lung cancer with mutated EGFR. N Engl J Med. 2010;362(25):2380-8.

19. Mitsudomi T, Morita S, Yatabe Y, et al. Gefitinib versus cisplatin plus docetaxel in patients with non-small-cell lung cancer harbouring mutations of the epidermal growth factor receptor (WJTOG3405): an open label, randomised phase 3 trial. Lancet Oncol. 2010;11(2):121-8.

20. Mok TS, Wu YL, Thongprasert S, et al. Gefitinib or carboplatinpaclitaxel in pulmonary adenocarcinoma. $\mathrm{N}$ Engl $\mathrm{J}$ Med. 2009;361(10):947-57.

21. Rosell R, Carcereny E, Gervais R, et al. Erlotinib versus standard chemotherapy as first-line treatment for European patients with advanced EGFR mutation-positive non-small-cell lung cancer (EURTAC): a multicentre, open-label, randomised phase 3 trial. Lancet Oncol. 2012;13(3):239-46.

22. Wu Y-L, Liam C-K, Zhou C, et al. First-line erlotinib versus cisplatin/gemcitabine (GP) in patients with advanced EGFR mutation-positive non-small-cell lung cancer (NSCLC): interim analyses from the Phase 3, open-label, ENSURE study [abstract no. P1-11-021]. J Thorac Oncol. 2013;8(Suppl. 2):S603.

23. Zhou C, Wu YL, Chen G, et al. Erlotinib versus chemotherapy as first-line treatment for patients with advanced EGFR 
mutation-positive non-small-cell lung cancer (OPTIMAL, CTONG-0802): a multicentre, open-label, randomised, phase 3 study. Lancet Oncol. 2011;12(8):735-42.

24. Cheng X, Chen H. Tumor heterogeneity and resistance to EGFR-targeted therapy in advanced nonsmall cell lung cancer: challenges and perspectives. Onco Targets Ther. 2014;7: 1689-704.

25. Fukuoka M, Wu YL, Thongprasert $\mathrm{S}$, et al. Biomarker analyses and final overall survival results from a phase III, randomized, open-label, first-line study of gefitinib versus carboplatin/paclitaxel in clinically selected patients with advanced non-small-cell lung cancer in Asia (IPASS). J Clin Oncol. 2011;29(21): 2866-74.

26. Inoue A, Kobayashi K, Maemondo M, et al. Updated overall survival results from a randomized phase III trial comparing gefitinib with carboplatin-paclitaxel for chemo-naive non-small cell lung cancer with sensitive EGFR gene mutations (NEJ002). Ann Oncol. 2013;24(1):54-9.

27. Mitsudomi T, Morita S, Yatabe Y, et al. Updated overall survival results of WJTOG 3405, a randomized phase III trial comparing gefitinib $(\mathrm{G})$ with cisplatin plus docetaxel $(\mathrm{CD})$ as the first-line treatment for patients with non-small cell lung cancer harboring mutations of the epidermal growth factor receptor (EGFR) [abstract no. 7521]. J Clin Oncol. 2012;30(Suppl 15).

28. Yang J, Wu YL, Saijo S, et al. Efficacy outcomes in first-line treatment of advanced nsclc with gefitinib (G) vs carboplatin/paclitaxel $(\mathrm{C} / \mathrm{P})$ by epidermal growth factor receptor (EGFR) gene-copy number score and by most common EGFR mutation subtypes-exploratory data from IPASS [abstract no. 9132]. Eur J Cancer. 2011;47(Suppl 1):S633.

29. Yoshioka H, Mitsudomi T, Morita S, et al. Final overall survival results of WJTOG 3405, a randomized phase 3 trial comparing gefitinib (G) with cisplatin plus docetaxel (CD) as the first-line treatment for patients with non-small cell lung cancer (NSCLC) harboring mutations of the epidermal growth factor receptor (EGFR) [abstract no. 8117]. J Clin Oncol. 2014;32(Suppl 15).

30. Zhou $\mathrm{C}$, Wu YL, Liu X, et al. Overall survival (OS) results from OPTIMAL (CTONG0802), a phase III trial of erlotinib (E) versus carboplatin plus gemcitabine (GC) as first-line treatment for Chinese patients with EGFR mutation-positive advanced non-small cell lung cancer (NSCLC) [abstract no. 7520]. J Clin Oncol. 2012;30(Suppl 15).

31. Riely GJ, Politi KA, Miller VA, et al. Update on epidermal growth factor receptor mutations in non-small cell lung cancer. Clin Cancer Res. 2006;12(24):7232-41.

32. Sharma SV, Bell DW, Settleman J, et al. Epidermal growth factor receptor mutations in lung cancer. Nat Rev Cancer. 2007;7(3):169-81.

33. Spicer JF, Rudman SM. EGFR inhibitors in non-small cell lung cancer (NSCLC): the emerging role of the dual irreversible EGFR/HER2 inhibitor BIBW 2992. Target Oncol. 2010;5(4): 245-55.

34. Jackman DM, Miller VA, Cioffredi LA, et al. Impact of epidermal growth factor receptor and KRAS mutations on clinical outcomes in previously untreated non-small cell lung cancer patients: results of an online tumor registry of clinical trials. Clin Cancer Res. 2009;15(16):5267-73.

35. Rosell R, Moran T, Queralt C, et al. Screening for epidermal growth factor receptor mutations in lung cancer. N Engl J Med. 2009;361(10):958-67.

36. Gridelli C, de Marinis F, et al. Gefitinib as first-line treatment for patients with advanced non-small-cell lung cancer with activating epidermal growth factor receptor mutation: review of the evidence. Lung Cancer. 2011;71(3):249-57.

37. Food and Drug Administration. Information for Healthcare Professionals: Gefitinib (marketed as Iressa). 2015. http://www.
fda.gov/Drugs/DrugSafety/PostmarketDrugSafetyInformation forPatientsandProviders/DrugSafetyInformationforHeathcare Professionals/ucm085197.htm. Accessed 5 Feb 2015.

38. Food and Drug Administration. Erlotinib. 2015. http://www.fda. gov/Drugs/InformationOnDrugs/ApprovedDrugs/ucm352317. htm. Accessed 5 Feb 2015.

39. Garassino MC, Martelli O, Broggini M, et al. Erlotinib versus docetaxel as second-line treatment of patients with advanced non-small-cell lung cancer and wild-type EGFR tumours (TAILOR): a randomised controlled trial. Lancet Oncol. 2013;14(10):981-8.

40. Kawaguchi T, Ando M, Asami K, et al. Randomized phase III trial of erlotinib versus docetaxel as second- or third-line therapy in patients with advanced non-small-cell lung cancer: docetaxel and Erlotinib Lung Cancer Trial (DELTA). J Clin Oncol. 2014;32(18):1902-8.

41. Pao W, Miller VA, Politi KA, et al. Acquired resistance of lung adenocarcinomas to gefitinib or erlotinib is associated with a second mutation in the EGFR kinase domain. PLoS Med. 2005;2(3):e73.

42. Arcila ME, Oxnard GR, Nafa K, et al. Rebiopsy of lung cancer patients with acquired resistance to EGFR inhibitors and enhanced detection of the T790M mutation using a locked nucleic acid-based assay. Clin Cancer Res. 2011;17(5):1169-80.

43. Sequist LV, Waltman BA, Dias-Santagata D, et al. Genotypic and histological evolution of lung cancers acquiring resistance to EGFR inhibitors. Sci Transl Med. 2011;3(75):75ra26.

44. Inukai M, Toyooka S, Ito S, et al. Presence of epidermal growth factor receptor gene T790M mutation as a minor clone in nonsmall cell lung cancer. Cancer Res. 2006;66(16):7854-8.

45. Lin $Y$, Wang $X$, Jin $H$. EGFR-TKI resistance in NSCLC patients: mechanisms and strategies. Am J Cancer Res. 2014;4(5):411-35.

46. Bean J, Brennan C, Shih JY, et al. MET amplification occurs with or without T790M mutations in EGFR mutant lung tumors with acquired resistance to gefitinib or erlotinib. Proc Natl Acad Sci USA. 2007;104(52):20932-7.

47. Engelman JA, Zejnullahu K, Mitsudomi T, et al. MET amplification leads to gefitinib resistance in lung cancer by activating ERBB3 signaling. Science. 2007;316(5827):1039-43.

48. Peled N, Wynes MW, Ikeda N, et al. Insulin-like growth factor-1 receptor (IGF-1R) as a biomarker for resistance to the tyrosine kinase inhibitor gefitinib in non-small cell lung cancer. Cell Oncol (Dordr). 2013;36(4):277-88.

49. Takezawa K, Pirazzoli V, Arcila ME, et al. HER2 amplification: a potential mechanism of acquired resistance to EGFR inhibition in EGFR-mutant lung cancers that lack the second-site EGFRT790M mutation. Cancer Discov. 2012;2(10):922-33.

50. Sergina NV, Rausch M, Wang D, et al. Escape from HERfamily tyrosine kinase inhibitor therapy by the kinase-inactive HER3. Nature. 2007;445(7126):437-41.

51. Nurwidya F, Takahashi F, Murakami A, et al. Epithelial mesenchymal transition in drug resistance and metastasis of lung cancer. Cancer Res Treat. 2012;44(3):151-6.

52. Engelman JA, Zejnullahu K, Gale CM, et al. PF00299804, an irreversible pan-ERBB inhibitor, is effective in lung cancer models with EGFR and ERBB2 mutations that are resistant to gefitinib. Cancer Res. 2007;67(24):11924-32.

53. Nam HJ, Ching KA, Kan J, et al. Evaluation of the antitumor effects and mechanisms of PF00299804, a pan-HER inhibitor, alone or in combination with chemotherapy or targeted agents in gastric cancer. Mol Cancer Ther. 2012;11(2):439-51.

54. Janne PA, Ou SH, Kim DW, et al. Dacomitinib as first-line treatment in patients with clinically or molecularly selected advanced non-small-cell lung cancer: a multicentre, open-label, phase 2 trial. Lancet Oncol. 2014;15(13):1433-41. 
55. Ramalingam SS, Jänne PA, Moke T, et al. Dacomitinib versus erlotinib in patients with advanced-stage, previously treated non-small-cell lung cancer (ARCHER 1009): a randomised, double-blind, phase 3 trial. Lancet Oncol. 2014;15(12):1369-78.

56. Rabindran SK, Discafani CM, Rosfjord EC, et al. Antitumor activity of HKI-272, an orally active, irreversible inhibitor of the HER-2 tyrosine kinase. Cancer Res. 2004;64(11):3958-65.

57. Sequist LV, Besse B, Lynch TJ, et al. Neratinib, an irreversible pan-ErbB receptor tyrosine kinase inhibitor: results of a phase II trial in patients with advanced non-small-cell lung cancer. J Clin Oncol. 2010;28(18):3076-83.

58. Wong KK, Fracasso PM, Bukowski RM, et al. A phase I study with neratinib (HKI-272), an irreversible pan ErbB receptor tyrosine kinase inhibitor, in patients with solid tumors. Clin Cancer Res. 2009;15(7):2552-8.

59. Solca F, Dahl G, Zoephel A, et al. Target binding properties and cellular activity of afatinib (BIBW 2992), an irreversible ErbB family blocker. J Pharmacol Exp Ther. 2012;343(2):342-50.

60. Aurisicchio L, Marra E, Roscilli G, et al. The promise of antiErbB3 monoclonals as new cancer therapeutics. Oncotarget. 2012;3(8):744-58.

61. Li D, Ambrogio L, Shimamura T, et al. BIBW2992, an irreversible EGFR/HER2 inhibitor highly effective in preclinical lung cancer models. Oncogene. 2008;27(34):4702-11.

62. Food and Drug Administration. Gilotrif prescribing information. 2013. http://www.accessdata.fda.gov/drugsatfda_docs/label/2013/ 201292s000lbl.pdf. Accessed 5 Sept 2014.

63. European Medicines Agency. Giotrif-summary of product characteristics, annex 1. 2013. http://www.ema.europa.eu/docs/ en_GB/document_library/EPAR_-_Product_Information/human/ 002280/WC500152392.pdf.

64. Modjtahedi H, Cho BC, Michel MC, et al. A comprehensive review of the preclinical efficacy profile of the ErbB family blocker afatinib in cancer. Naunyn Schmiedebergs Arch Pharmacol. 2014;387(6):505-21.

65. Kwak EL, Sordella R, Bell DW, et al. Irreversible inhibitors of the EGF receptor may circumvent acquired resistance to gefitinib. Proc Natl Acad Sci USA. 2005;102(21):7665-70.

66. Sequist LV, Yang JC, Yamamoto N, et al. Phase III study of afatinib or cisplatin plus pemetrexed in patients with metastatic lung adenocarcinoma with EGFR mutations. J Clin Oncol. 2013;31(27):3327-34.

67. Wu YL, Zhou C, Hu CP, et al. Afatinib versus cisplatin plus gemcitabine for first-line treatment of Asian patients with advanced non-small-cell lung cancer harbouring EGFR mutations (LUX-Lung 6): an open-label, randomised phase 3 trial. Lancet Oncol. 2014;15(2):213-22.

68. Yang JC, Wu YL, Schuler M, et al. Afatinib versus cisplatinbased chemotherapy for EGFR mutation-positive lung adenocarcinoma (LUX-Lung 3 and LUX-Lung 6): analysis of overall survival data from two randomised, phase 3 trials. Lancet Oncol. 2015;16(2):141-51.

69. Langer CJ. Epidermal growth factor receptor inhibition in mutation-positive non-small-cell lung cancer: is afatinib better or simply newer? J Clin Oncol. 2013;31(27):3303-6.

70. Yang JC, Hirsh V, Schuler M, et al. Symptom control and quality of life in LUX-Lung 3: a phase III study of afatinib or cisplatin/pemetrexed in patients with advanced lung adenocarcinoma with EGFR mutations. J Clin Oncol. 2013;31(27): 3342-50.

71. Burotto M, Manasanch EE, Wilkerson J, et al. Gefitinib and erlotinib in metastatic non-small cell lung cancer: a meta-analysis of toxicity and efficacy of randomized clinical trials. Oncologist. 2015;20(4):400-10.

72. Haspinger ER, Agustoni F, Torri V, et al. Is there evidence for different effects among EGFR-TKIs? Systematic review and meta-analysis of EGFR tyrosine kinase inhibitors (TKIs) versus chemotherapy as first-line treatment for patients harboring EGFR mutations. Crit Rev Oncol Hematol. 2015;94(2):213-27.

73. Liang W, Wu X, Fang W, et al. Network meta-analysis of erlotinib, gefitinib, afatinib and icotinib in patients with advanced non-small-cell lung cancer harboring EGFR mutations. PLoS One. 2014;9(2):e85245.

74. Popat S, Mok T, Yang JC, et al. Afatinib in the treatment of EGFR mutation-positive NSCLC-a network meta-analysis. Lung Cancer. 2014;85(2):230-8.

75. Yang JC, Shih JY, Su WC, et al. Afatinib for patients with lung adenocarcinoma and epidermal growth factor receptor mutations (LUX-Lung 2): a phase 2 trial. Lancet Oncol. 2012;13(5): 539-48.

76. Yang JC, Sequist LV, Geater SL, et al. Activity of afatinib in uncommon epidermal growth factor receptor (EGFR) mutations: findings from three trials of afatinib in EGFR mutation-positive lung cancer [abstract no. O03.05]. J Thorac Oncol. 2013;8(Suppl 2):S141.

77. Schuler M, Yang JC, Sequist LV, et al. Efficacy of afatinib vs. chemotherapy in treatment-naïve patients with non-small cell lung cancer (NSCLC) harbouring activating EGFR mutations with or without metastatic brain disease [abstract no. MO07.13]. J Thorac Oncol. 2013;8(Suppl 2):S294.

78. Hoffknecht P, Tufman A, Wehler T, et al. Efficacy of the irreversible ErbB family blocker afatinib in epidermal growth factor receptor (EGFR) tyrosine kinase inhibitor (TKI)-pretreated nonsmall-cell lung cancer patients with brain metastases or leptomeningeal disease. J Thorac Oncol. 2015;10(1):156-63.

79. Wu Y-L, Sequist LV, Hu C-P, et al. Overall survival (OS) in Asian patients with advanced non-small cell lung cancer (NSCLC) harboring common (Del19/L858R) epidermal growth factor receptor (EGFR) mutations: combined analysis of two large open-label phase III studies (LUX-Lung 3 [LL3] and LUX-Lung 6 [LL6]) comparing afatinib with chemotherapy [abstract no. A-0142]. Asia Pacific lung cancer conference (APLCC), p. 6, 8 November 2014; Kuala Lumpur, Malaysia.

80. Kato T, Yoshioka H, Okamoto I, et al. Japanese subgroup analysis in a phase III study of afatinib (A) compared with cisplatin plus pemetrexed $(\mathrm{CP})$ in treatment-naive patients (pts) with metastatic lung adenocarcinoma harboring EGFR mutations (mut): LUX-Lung 3 study [abstract no. O-125]. 55th annual meeting of the Japan Lung Cancer Society (JLCS), p. 14, 6 November 2014; Kyoto, Japan.

81. Wu Y-L, Zhou C, Hu C-P, et al. Overall survival (OS) with afatinib (A) vs gemcitabine/cisplatin (GC) in treatment-naive Chinese patients (pts) with advanced non-small cell lung cancer (NSCLC) harboring EGFR mutations (mut): subpopulation analysis from LUX-Lung 6 (LL6). 17th annual meeting of Chinese Society for Clinical Oncology (CSCO), p. 17, 21 September 2014; Xiamen, China.

82. Hutchinson L. Targeted therapies: LUX-Lung trials-not all mutations are created equal. Nat Rev Clin Oncol. 2015;12(3): 127.

83. Hirsh V. Are the data on quality of life and patient reported outcomes from clinical trials of metastatic non-small-cell lung cancer important? World J Clin Oncol. 2013;4(4):82-4.

84. Lacouture ME, Schadendorf D, Chu CY, et al. Dermatologic adverse events associated with afatinib: an oral ErbB family blocker. Expert Rev Anticancer Ther. 2013;13(6):721-8.

85. Yang JC, Reguart N, Barinoff J, et al. Diarrhea associated with afatinib: an oral ErbB family blocker. Expert Rev Anticancer Ther. 2013;13(6):729-36.

86. Miller VA, Hirsh V, Cadranel J, et al. Afatinib versus placebo for patients with advanced, metastatic non-small-cell lung cancer after failure of erlotinib, gefitinib, or both, and one or two 
lines of chemotherapy (LUX-Lung 1): a phase $2 b / 3$ randomised trial. Lancet Oncol. 2012;13(5):528-38.

87. Hirsh V, Cadranel J, Cong XJ, et al. Symptom and quality of life benefit of afatinib in advanced non-small-cell lung cancer patients previously treated with erlotinib or gefitinib: results of a randomized phase IIb/III trial (LUX-Lung 1). J Thorac Oncol. 2013;8(2):229-37.

88. Jackman D, Pao W, Riely GJ, et al. Clinical definition of acquired resistance to epidermal growth factor receptor tyrosine kinase inhibitors in non-small-cell lung cancer. J Clin Oncol. 2010;28(2):357-60.

89. Schuler MH, Yang CH, Park K, et al. Continuation of afatinib beyond progression: Results of a randomized, open-label, phase III trial of afatanib plus paclitaxel (P) versus investigator's choice chemotherapy (CT) in patients (pts) with metastatic nonsmall cell lung cancer (NSCLC) progressed on erlotinib/gefitinib (E/G) and afatanib-LUX-Lung 5 (LL5) [abstract no. 8019]. J Clin Oncol. 2014;32(Suppl 15).

90. Planchard D, Park K, Yang J. Patient-reported outcomes (PROs) in patients (pts) with advanced non-small cell lung cancer (NSCLC) receiving afatinib (A) monotherapy followed by $\mathrm{A}+$ paclitaxel $(\mathrm{A}+\mathrm{P})$ vs investigator's choice of single-agent chemotherapy (IC): Lux-Lung 5 (LL5). [abstract no. 1265P]. Ann Oncol. 2014;25(Suppl 4):iv426-iv470.

91. Mok TSK, Wu Y, Nakagawa K, et al. Gefitinib/chemotherapy vs chemotherapy in epidermal growth factor receptor (EGFR) mutation-positive non-small-cell lung cancer (NSCLC) after progression on first-line gefitinib: the phase III, randomised IMPRESS study [abstract no. LBA2_PR]. Ann Oncol. 2014;25(Suppl 4).

92. Peters S, Zimmermann S, Adjei AA. Oral epidermal growth factor receptor tyrosine kinase inhibitors for the treatment of non-small cell lung cancer: comparative pharmacokinetics and drug-drug interactions. Cancer Treat Rev. 2014;40(8):917-26.

93. Wind S, Schmid M, Erhardt J, et al. Pharmacokinetics of afatinib, a selective irreversible ErbB family blocker, in patients with advanced solid tumours. Clin Pharmacokinet. 2013;52(12): 1101-9.

94. Stopfer P, Marzin K, Narjes H, et al. Afatinib pharmacokinetics and metabolism after oral administration to healthy male volunteers. Cancer Chemother Pharmacol. 2012;69(4):1051-61.

95. Ang J, Mikropoulos C, Stavridi F, et al. A phase I study of daily BIBW 2992, an irreversible EGFR/HER-2 dual kinase inhibitor, in combination with weekly paclitaxel. J Clin Oncol. 2009;27(Suppl. 15):e14541.

96. Awada AH, Dumez H, Hendlisz A, et al. Phase I study of pulsatile 3-day administration of afatinib (BIBW 2992) in combination with docetaxel in advanced solid tumors. Invest New Drugs. 2013;31(3):734-41.

97. Chu QS, Sangha R, Hotte SJ, et al. A phase I, dose-escalation trial of continuous- and pulsed-dose afatinib combined with pemetrexed in patients with advanced solid tumors. Invest New Drugs. 2014;32(6):1226-35.

98. Cortes J, Dieras V, Ro J, et al. Randomized Phase II trial of afatinib alone or with vinorelbine versus investigator's choice of treatment in patients with HER2-positive breast cancer with progressive brain metastases after trastuzumab and/or lapatinibbased therapy: LUX-Breast 3 [abstract no. P5-19-07]. San Antonio Breast Cancer Symposium, 9-13 December 2014; San Antonio, TX.

99. Harbeck N, Huang C-S, Hurvitz SA, et al. Randomized Phase III trial of afatinib plus vinorelbine versus trastuzumab plus vinorelbine in patients with HER2-overexpressing metastatic breast cancer who had progressed on one prior trastuzumab treatment: LUX-Breast 19 [abstract no. P5-19-01]. San Antonio
Breast Cancer Symposium; 9-13 December 2014; San Antonio, TX.

100. Marshall J, Hwang J, Eskens FA, et al. A Phase I, open-label, dose escalation study of afatinib, in a 3-week-on/1-week-off schedule in patients with advanced solid tumors. Invest New Drugs. 2013;31(2):399-408.

101. Reardon DA, Nabors LB, Mason WP, et al. Phase I/randomized phase II study of afatinib, an irreversible ErbB family blocker, with or without protracted temozolomide in adults with recurrent glioblastoma. Neuro Oncol. 2015;17(3):430-9.

102. Ring A, Wheatley D, Hatcher H, et al. Phase I study to assess the combination of afatinib with trastuzumab in patients with advanced or metastatic HER2-positive breast cancer. Clin Cancer Res. 2014. doi:10.1158/1078-0432.CCR-14-1812.

103. Vermorken JB, Rottey S, Ehrnrooth E, et al. A phase Ib, openlabel study to assess the safety of continuous oral treatment with afatinib in combination with two chemotherapy regimens: cisplatin plus paclitaxel and cisplatin plus 5-fluorouracil, in patients with advanced solid tumors. Ann Oncol. 2013;24(5):1392-400.

104. Janjigian YY, Smit EF, Groen HJ, et al. Dual inhibition of EGFR with afatinib and cetuximab in kinase inhibitor-resistant EGFR-mutant lung cancer with and without T790 mutations. Cancer Discov. 2014;4(9):1036-45.

105. Janne PA, Ramalingam SS, Yang JC-H, et al. Clinical activity of the mutant-selective EGFR inhibitor AZD9291 in patients (pts) with EGFR inhibitor-resistant non-small cell lung cancer (NSCLC). [abstract no. 8009]. J Clin Oncol. 2014;32(Suppl 15).

106. Kim DW, Lee DH, Kang JH, et al. Clinical activity and safety of HM61713, an EGFR-mutant selective inhibitor, in advanced non-small cell lung cancer (NSCLC) patients (pts) with EGFR mutations who had received EGFR tyrosine kinase inhibitors (TKIs) [abstract no. 8011]. J Clin Oncol. 2014;32(Suppl 15).

107. Sequist LV, Soria JC, Gadgeel SM, et al. First-in-human evaluation of CO-1686, an irreversible, highly selective tyrosine kinase inhibitor of mutations of EGFR (activating and T790M) [abstract no. 8010]. J Clin Oncol. 2014;32(Suppl 15).

108. Bryant A, Cerfolio RJ. Differences in epidemiology, histology, and survival between cigarette smokers and never-smokers who develop non-small cell lung cancer. Chest. 2007;132(1):185-92.

109. Dearden S, Stevens J, Wu YL, et al. Mutation incidence and coincidence in non small-cell lung cancer: meta-analyses by ethnicity and histology (mutMap). Ann Oncol. 2013;24(9): 2371-6.

110. Park K, Kim J, Schuler M. Afatinib (A) followed by A + paclitaxel $(\mathrm{P})$ or investigator's choice of single-agent chemotherapy (IC) in patients (pts) with advanced squamous cell carcinoma (SCC) of the lung: subgroup analysis of Lux-Lung 5 (LL5). [abstract no. 1263P]. Ann Oncol. 2014;25(Suppl 4): iv443-iv444.

111. Seiwert TY, Fayette J, Cupissol D, et al. A randomized, phase 2 study of afatinib versus cetuximab in metastatic or recurrent squamous cell carcinoma of the head and neck. Ann Oncol. 2014;25(9):1813-20.

112. Dacic S, Flanagan M, Cieply K, et al. Significance of EGFR protein expression and gene amplification in non-small cell lung carcinoma. Am J Clin Pathol. 2006;125(6):860-5.

113. Hirsch FR, Varella-Garcia M, Bunn PA Jr, et al. Epidermal growth factor receptor in non-small-cell lung carcinomas: correlation between gene copy number and protein expression and impact on prognosis. J Clin Oncol. 2003;21(20):3798-807.

114. Lee HJ, Xu X, Choe G, et al. Protein overexpression and gene amplification of epidermal growth factor receptor in nonsmall cell lung carcinomas: comparison of four commercially available antibodies by immunohistochemistry and fluorescence in situ hybridization study. Lung Cancer. 2010;68(3):375-82. 
115. Cancer Genome Atlas Research Network. Comprehensive genomic characterization of squamous cell lung cancers. Nature. 2012;489(7417):519-25.

116. Dhanasekaran SM, Alejandro BO, Chen G, et al. Transcriptome meta-analysis of lung cancer reveals recurrent aberrations in NRG1 and Hippo pathway genes. Nat Commun. 2014;5:5893.

117. Heinmoller P, Gross C, Beyser K, et al. HER2 status in nonsmall cell lung cancer: results from patient screening for enrollment to a phase II study of herceptin. Clin Cancer Res. 2003;9(14):5238-43.

118. Soria J-C, Felip E, Cobo M, et al. Afatinib (A) vs erlotinib (E) as second-line therapy of patients (pts) with advanced squamous cell carcinoma (SCC) of the lung following platinum-based chemotherapy: Overall survival (OS) analysis from the global phase III trial LUX-Lung 8 (LL8) [abstract no. 8002]. J Clin Oncol. 2015;33(Suppl). 